\title{
COAL CLEANING BY GAS AGGLOMERATION
}

Semi-Annual Technical Progress Report

April 1, 1998 - September 30, 1998

T. D. Wheelock

Principle Investigator

Meiyu Shen

Graduate Assistant

Royce Abbott

Research Assistant

Issued: September 1998

DOE Grant No. DE-FG-26-97FT97261--02

Chemical Engineering Department and

Center for Coal and the Environment

2114 Sweeney Hall

Iowa State University

Ames, IA 50011-2230 


\section{DISCLAIMER}

This report was prepared as an account of work sponsored by an agency of the United States Government. Neither the United States Government nor any agency thereof, nor any of their employees, makes any warranty, express or implied, or assumes any legal liability or responsibility for the accuracy, completeness, or usefulness of any information, apparatus, product, or process disclosed, or represents that its use would not infringe privately owned rights. Reference herein to any specific commercial product, process, or service by trade name, trademark, manufacturer, or otherwise does not necessarily constitute or imply its endorsement, recommendation, or favoring by the United States Government or any agency thereof. The views and opinions of the authors expressed herein do not necessarily state or reflect those of the United States Government or any agency thereof. 


\section{TABLE OF CONTENTS}

Executive Summary $\quad 1$

Introduction $\quad 2$

Experimental Method 3

Agglomeration System 3

Agglomeration Procedure and Materials 4

$\begin{array}{ll}\text { Results and Discussion } & 6\end{array}$

$\begin{array}{ll}\text { Conclusions } & 12\end{array}$

$\begin{array}{ll}\text { Reference } & 13\end{array}$ 


\title{
COAL CLEANING BY GAS AGGLOMERATION
}

Semi-Annual Technical Progress Report

April 1, 1998 - September 30, 1998

T. D. Wheelock, Principal Investigator

\begin{abstract}
The agglomeration of ultrafine-size coal particles in an aqueous suspension by means of microscopic gas bubbles was demonstrated in numerous experiments with a scale model mixing system. Coal samples from both the Pittsburgh No. 8 Seam and the Upper Freeport Seam were used for these experiments. A small amount of i-octane was added to facilitate the process. Microscopic gas bubbles were generated by saturating the water used for suspending coal particles with gas under pressure and then reducing the pressure. Microagglomerates were produced which appeared to consist of gas bubbles encapsulated in coal particles. Since dilute particle suspensions were employed, it was possible to monitor the progress of agglomeration by observing changes in turbidity. By such means it became apparent that the rate of agglomeration depends on the concentration of microscopic gas bubbles and to a lesser extent on the concentration of i-octane. Similar results were obtained with both Pittsburgh No. 8 coal and Upper Freeport coal.
\end{abstract}




\section{EXECUTIVE SUMMARY}

The overall purpose of this project is to demonstrate the technical feasibility of the gas agglomeration methods for cleaning coal. In this method fine-size coal particles are suspended in water and selectively agglomerated by microscopic gas bubbles. A small amount of oil may be added to enhance the hydrophobicity of the coal.

Numerous agglomeration tests were conducted in which a concentrated coal slurry was mixed with a colloidal dispersion of gas bubbles to produce a dilute suspension which agglomerated rapidly under vigorous agitation. Both Pittsburgh No. 8 coal and Upper Freeport coal were utilized in a finely ground form. The colloidal dispersion of microscopic bubbles was produced by saturating water with gas under pressure, adding a small amount of i-octane, and reducing the pressure to atmospheric as the mixture was stirred. The i-octane appeared to stabilize the fog-like dispersion. After the dispersion of bubbles and coal slurry were mixed, the progress of agglomeration was monitored by observing changes in the turbidity of the system.

The test results showed that the apparent rate of agglomeration increased substantially with an increase in the concentration of microscopic gas bubbles, whereas it increased only slightly with an increase in i-octane concentration. Similar results were observed with both Pittsburgh No. 8 coal and Upper Freeport coal. 


\section{INTRODUCTION}

The gas agglomeration method of cleaning coal involves contacting fine-size coal particles with microscopic and/or sub-microscopic gas bubbles in a well-mixed aqueous suspension to produce agglomerates which are held together by very small gas bridges. Small amounts of oil seem to be required with some types of coal. However, the amount of oil is much less than is required for the oil agglomeration method of cleaning coal. Since the gas-agglomerated particles tend of float, they can be recovered from a suspension by floating and skimming.

Equipment and experimental procedures have been developed for generating microscopic gas bubbles and for demonstrating gas agglomeration of coal particles (1). The particles and a small amount of oil are suspended in water which first has been saturated with a dissolved gas, sometimes under pressure. When the suspension is warmed or the pressure is released, microscopic gas bubbles are generated which serve to bind the coal particles into agglomerates. In the case of dilute suspensions, the progress of agglomeration can be monitored by observing changes in the turbidity of a suspension.

Preliminary experiments were conducted previously with Pittsburgh No. 8 coal using small amounts of i-octane to enhance the hydrophobicity of the material (1). Most of the experiments were conducted by first mixing a ground coal paste with water which had been cooled to $2-4^{\circ} \mathrm{C}$ and saturated with gas under atmospheric pressure. As the resulting suspension was agitated, its temperature rose gradually and microscopic gas bubbles were produced causing particle agglomeration which was indicated by a decrease in turbidity. Agglomeration tests conducted to study the effects of different parameters showed that extensive agglomeration occurred when as little as $1.0 \mathrm{v} / \mathrm{w} \%$ i-octane was 
employed. Also the initial rate of agglomeration was observed to increase with an increase in either agitator speed or initial dissolved gas concentration.

The results of an agglomeration test were also reported in which Pittsburgh No. 8 coal particles were mixed with a colloidal dispersion of air bubbles in water (1). The dispersion was prepared by first saturating the water with air under pressure at room temperature, adding a small amount of i-octane, and then releasing the pressure. When a concentrated slurry of coal particles and the colloidal suspension of gas bubbles were combined and mixed vigorously, agglomeration proceeded rapidly. Furthermore, it was shown that the process of agglomeration could be reversed by pressurizing the system, which caused the gas bubbles to redissolve.

Further agglomeration tests have been conducted and the results are reported below. Each of these tests was conducted by combining a concentrated slurry of coal particles with a colloidal dispersion of gas bubbles as described above. Both Pittsburgh No. 8 coal and Upper Freeport coal were utilized, and the effects of different parameters including i-octane concentration and gas concentration were investigated.

\section{EXPERIMENTAL METHOD}

\section{Agglomeration System}

Agglomeration tests were conducted with the system which could be pressurized and which was described previously in detail (1). As Figure 1 indicates, the system consists of a stirred tank in which particles are agglomerated, a surge tank in which water is saturated with gas under pressure, a coal storage tank in which a concentrated slurry of particles is placed initially, a pump used for introducing the slurry into the stirred tank, 


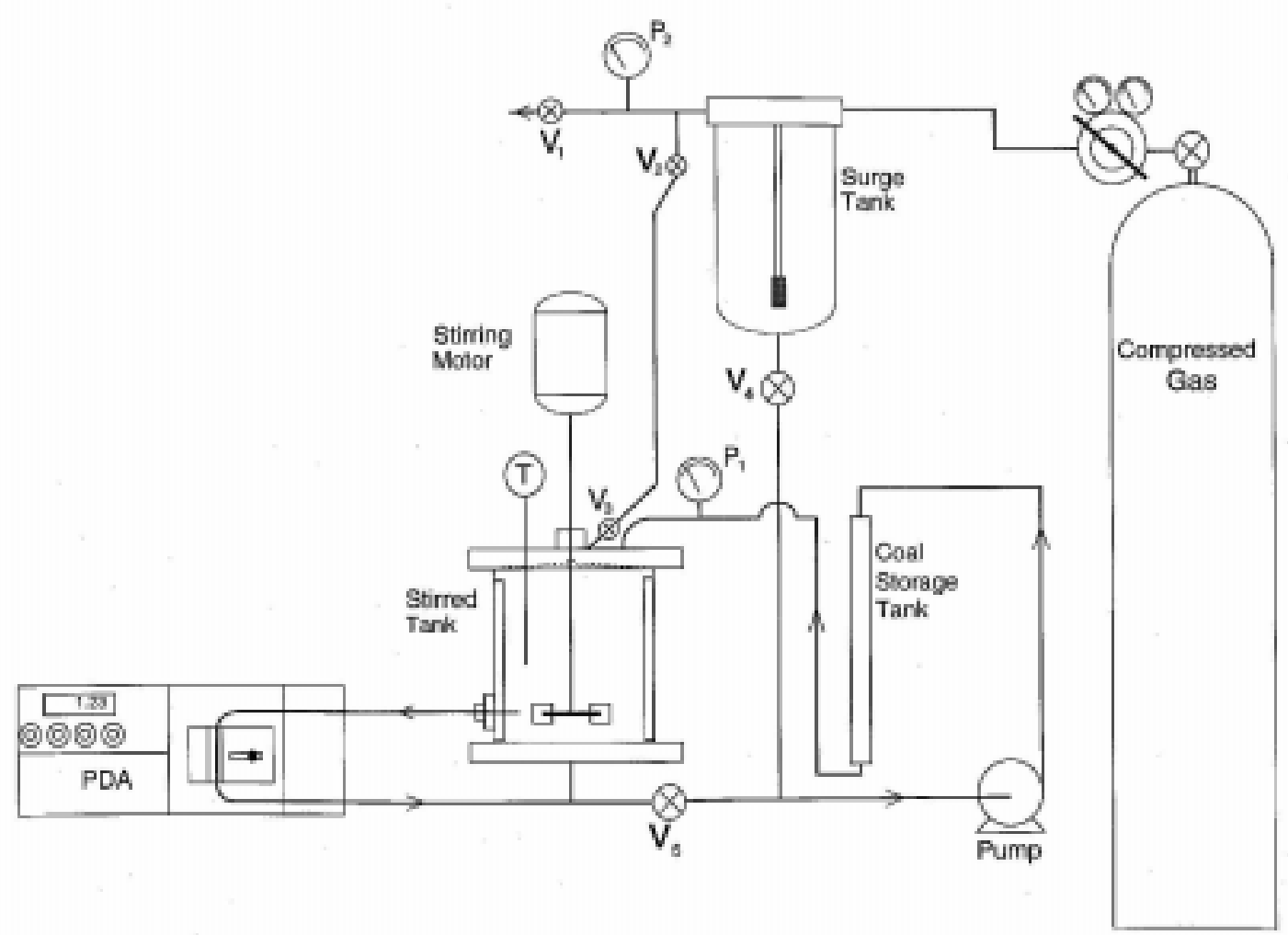

Figure 1. Experimental system used for investigating the influence of gas bubble concentration on coal particle agglomeration.

and a photometric dispersion analyzer (PDA) for measuring the turbidity of the suspension. The stirred tank has an inside diameter of $11.43 \mathrm{~cm}$ and inside height of $11.43 \mathrm{~cm}$, and it is fitted with four vertical baffles. A cooling coil is attached to the bottom of the tank. The tank is equipped with a variable speed agitator which drives a $3.65 \mathrm{~cm}$ diameter turbine impeller with six vertical flat blades mounted on a horizontal disk. The impeller disk is located $2.54 \mathrm{~cm}$ above the tank bottom.

\section{$\underline{\text { Agglomeration Procedure and Materials }}$}

Coal samples were utilized from both the Pittsburgh No. 8 Seam in Belmont County, Ohio, and the Upper Freeport Seam in Indiana County, Pennsylvania. These coals were found to contain $27 \mathrm{wt} . \%$ and $25.5 \mathrm{wt} . \%$ ash, respectively. The samples were 
crushed in stages and then ground as a concentrated slurry in a stirred ball mill to produce particles having a projected area mean particle diameter of $4 \mu \mathrm{m}$ for the Pittsburgh coal and $5 \mu \mathrm{m}$ for the Upper Freeport coal. After grinding, the slurry was partially dewatered and stored as a paste is a refrigerator set at $5^{\circ} \mathrm{C}$. For an agglomeration test, ground coal was suspended in deionized water, and i-octane with an indicated purity of $99.5 \%$ was used for enhancing the hydrophobicity of the material.

For conducting a batch agglomeration test or run, the mixing tank was first filled completely with deionized water which had been saturated with gas under pressure at room temperature $\left(22-24^{\circ} \mathrm{C}\right)$. After an agitator speed of $2000 \mathrm{rpm}$ was established, a measured amount of pure i-octane was introduced. The mixture was conditioned for 1 - 2 min., and then the pressure was reduced to atmospheric which allowed the dissolved gas to come out of solution in the form of microscopic bubbles. A concentrated coal slurry was then introduced quickly so as to provide an ultimate solids concentration of $1.0 \mathrm{w} / \mathrm{w} \%$. Particles started to agglomerate immediately, and the process of agglomeration was monitored by observing the changing turbidity. As agglomeration proceeded the agitator speed was held at $2000 \mathrm{rpm}$ and the temperature of the suspension was kept close to room temperature by circulating water through a cooling coil attached to the bottom of the mixing tank. A run was continued until the turbidity approached a constant value. At the end of a run, a sample of the suspension was examined with an optical microscope to determine the size range of the agglomerates.

The results of the agglomeration tests are reported below in terms of the relative turbidity change which took place during a given test. The relative turbidity change $\left(\Delta \tau_{\mathrm{r}}\right)$ in percent is defined by the following expression: 


$$
\Delta \tau_{\mathrm{r}}=\left[\left(\tau_{\mathrm{o}}-\tau\right) / \tau_{\mathrm{o}}\right] 100
$$

where $\tau_{\mathrm{o}}$ represents the initial turbidity of the unagglomerated suspension and $\tau$ represents the turbidity after agglomeration has taken place. It is apparent that as agglomeration takes place the relative turbidity change will increase while the absolute turbidity decreases.

\section{RESULTS AND DISCUSSION}

Several agglomeration tests were carried out to determine the reproducibility of the results and to see how the results would be affected by the type of coal. Therefore, two tests were conducted with Pittsburgh coal and two tests with Upper Freeport coal. For each test enough water was first saturated with air under an absolute pressure of $205 \mathrm{kPa}$ (15 psi gauge pressure) at room temperature $\left(24^{\circ} \mathrm{C}\right)$ to fill the stirred tank. Sufficient i-octane was then introduced to provide a concentration of $2.5 \mathrm{v} / \mathrm{w} \%$ based on the weight of coal (i.e., $0.025 \mathrm{ml} / \mathrm{g}$ coal). As the mixture was agitated at $2000 \mathrm{rpm}$, the system pressure was reduced to atmospheric pressure over a period of 30 to $60 \mathrm{~s}$ which created a fog-like colloidal dispersion. Soon thereafter a concentrated slurry of coal particles was transferred from the coal storage tank to the mixing tank, which created a suspension with $1.0 \mathrm{w} / \mathrm{w} \%$ solids. While the initial turbidity of the suspension was very large, the turbidity decreased rapidly as the particles were agglomerated. Consequently, the relative turbidity change $\left(\Delta \tau_{\mathrm{r}}\right)$ increased rapidly as indicated by Figure 2 . Within 10 to 15 min., $\Delta \tau_{\mathrm{r}}$ approach a final level which indicated completion of the process of agglomeration.

Figure 2 indicates that the test results were highly reproducible for each type of coal. It also suggests that the apparent rate of agglomeration was higher for Pittsburgh 


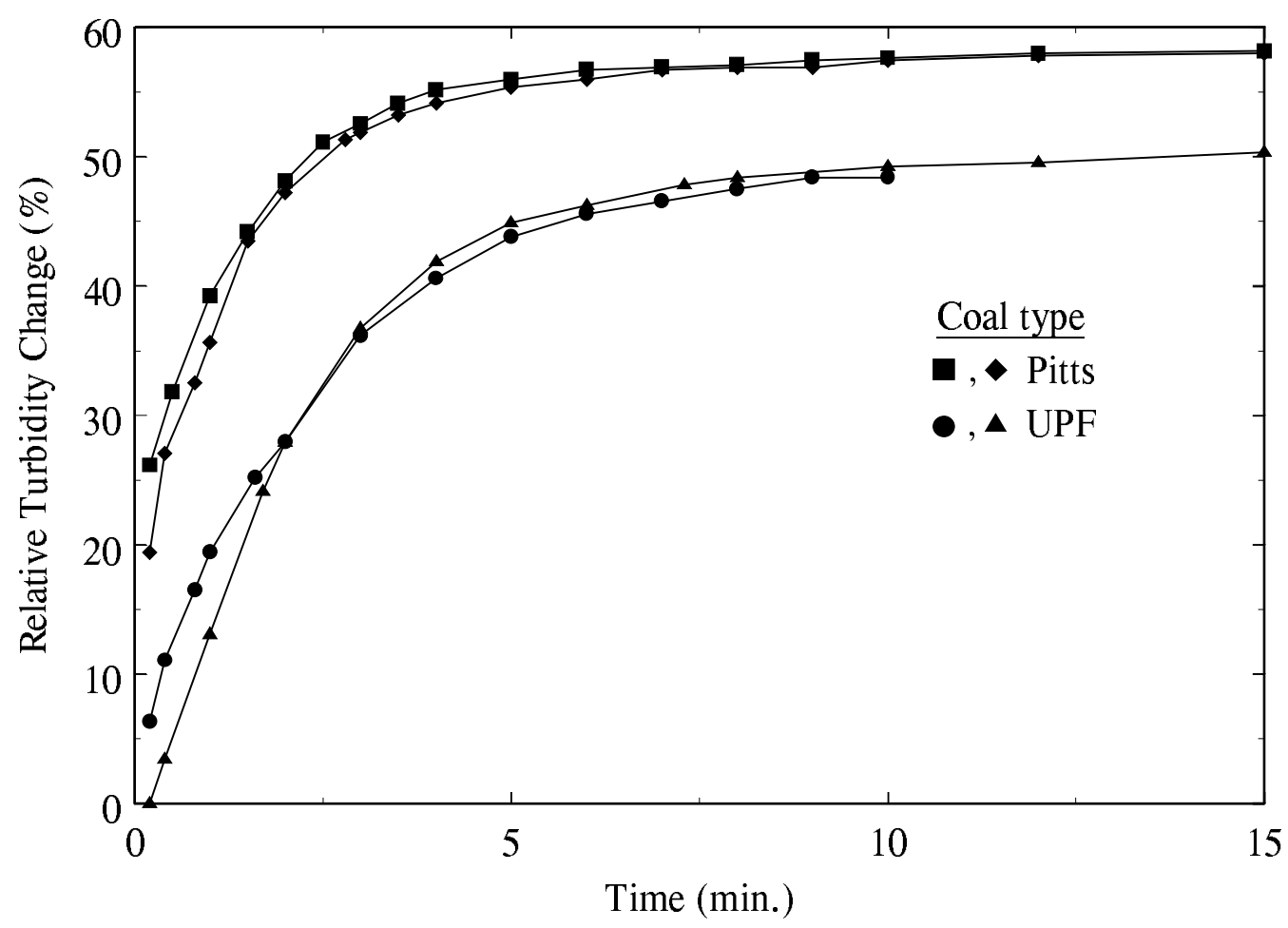

Figure 2. Agglomeration test results with Pittsburgh No. 8 coal and Upper Freeport (UPF) coal.

coal than for Upper Freeport coal, which was unexpected since the hydrophobicity of Pittsburgh coal is normally less than that of Upper Freeport coal. However, since the coals had been stored for a long time, albeit under argon, their surface properties might have changed. Also the particle size distributions of the coals were not exactly the same which could have influenced the results.

Additional tests were conducted with both types of coal to study the effect of gas bubble concentration on the apparent rate of agglomeration. The gas bubble concentration was varied among runs by saturating the water with air at different pressures, since the dissolved gas concentration would have been directly proportional to pressure according to Henry's Law. In each case the gas-saturated water was treated with enough i-octane to provide a concentration of $2.5 \mathrm{v} / \mathrm{w} \%$ based on the weight of coal. 
After the pressure was reduced to atmospheric, coal was introduced and agglomeration proceeded at a rate which appeared to reflect the initial gas concentrations (Figures 3 and 4). It can be seen that the value of $\Delta \tau_{\mathrm{r}}$ reached during the first $5 \mathrm{~min}$. rose with increasing gas saturation pressure. Also it is apparent that increasing the saturation pressure from $136 \mathrm{kPa}$ to $170 \mathrm{kPa}$ had a greater effect than increasing the saturation pressure from $170 \mathrm{kPa}$ to $205 \mathrm{kPa}$.

The effect of gas concentration on the apparent rate of agglomeration was also observed by comparing the results of tests made under similar conditions except for the type of gas. In one case the water was first saturated with air at $136 \mathrm{kPa}(5 \mathrm{psig})$ while in another case the water was first saturated with carbon dioxide under similar conditions. Since carbon dioxide is much more soluble than air in water, the dissolved gas concentration was much higher when carbon dioxide was employed. For these tests an i-octane concentration of $2.5 \mathrm{v} / \mathrm{w} \%$ was employed. The results achieved with Pittsburgh coal are shown in Figure 5 and those achieved with Upper Freeport coal in Figure 6. In both cases, the apparent rate of agglomeration was greater with carbon dioxide than with air because of the greater concentration of carbon dioxide.

To see whether the concentration of i-octane had an effect on the apparent rate of agglomeration, the concentration was varied between tests made under similar conditions. For these tests the water was first saturated with air at $205 \mathrm{kPa}$ (15 psig). The results obtained with the different types of coal are indicated by Figures 7 and 8, respectively. The results suggest that the rate was affected only slightly by i-octane concentration, since the change in $\Delta \tau_{\mathrm{r}}$ during the first $10 \mathrm{~min}$. was only slightly greater with $2.5 \mathrm{v} / \mathrm{w} \%$ i-octane than with $1 \mathrm{v} / \mathrm{w} \%$. 


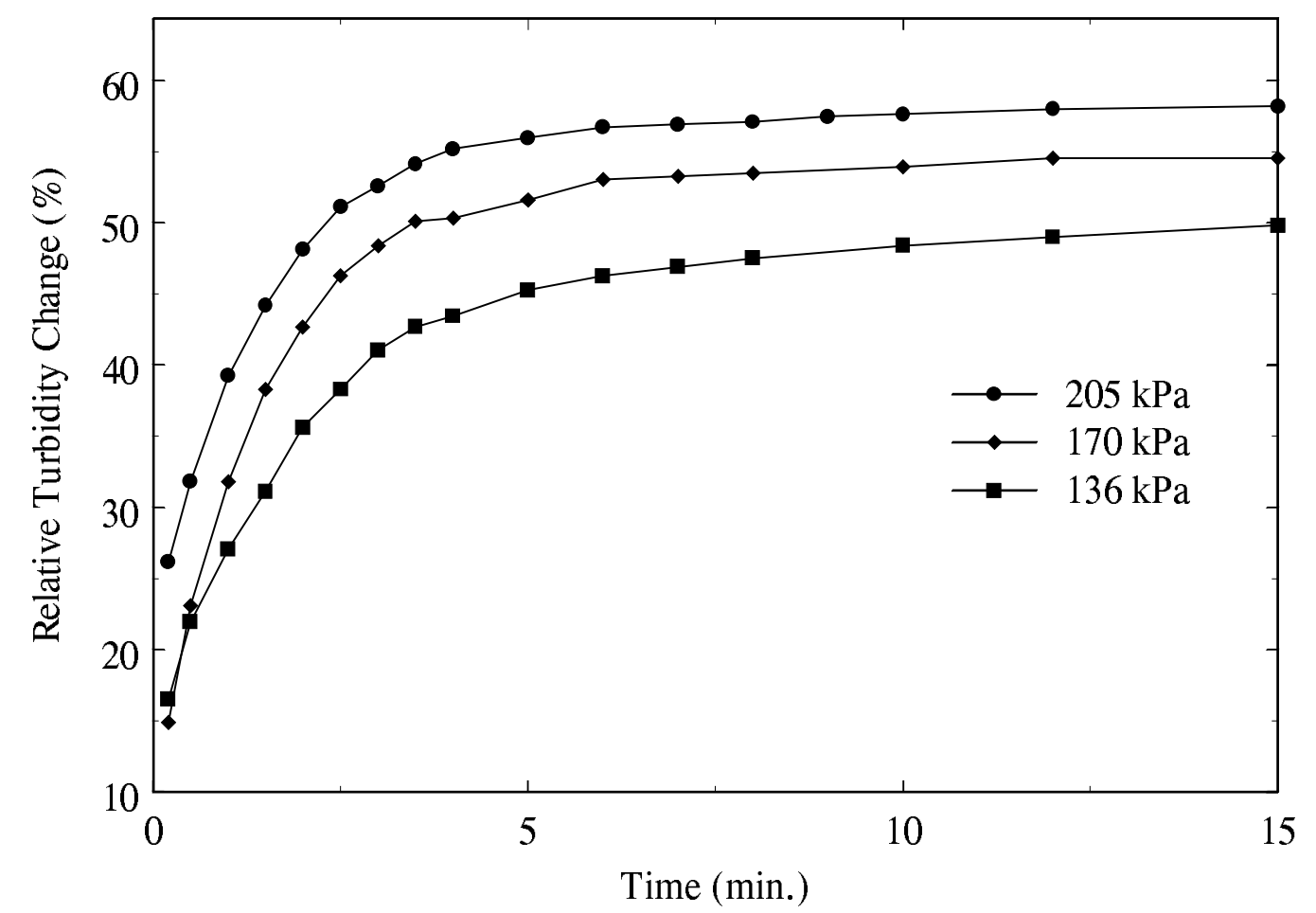

Figure 3. Effect of air saturation pressure on the agglomeration of Pittsburgh No. 8 coal.

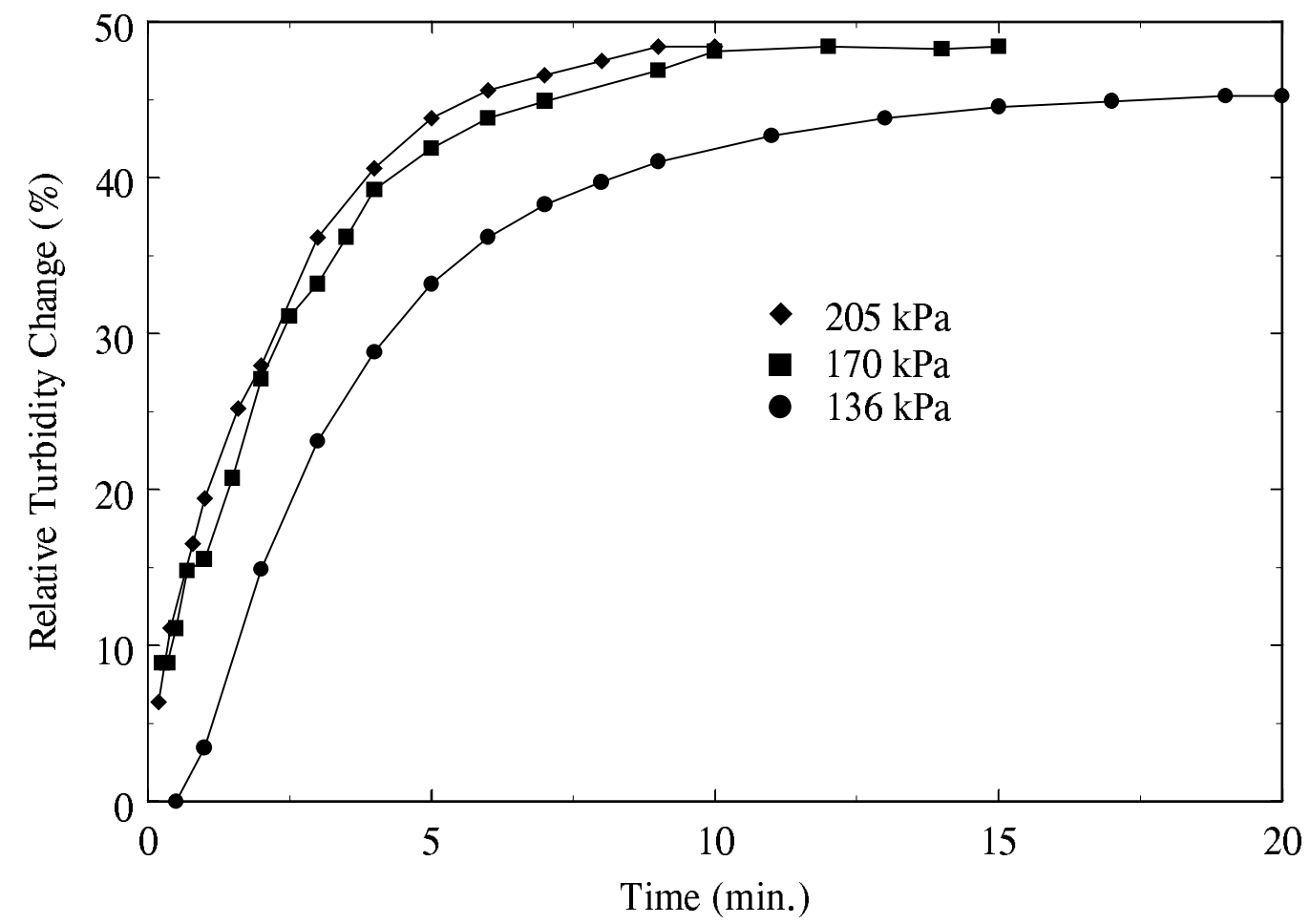

Figure 4. Effect of air saturation pressure on the agglomeration of Upper Freeport coal. 


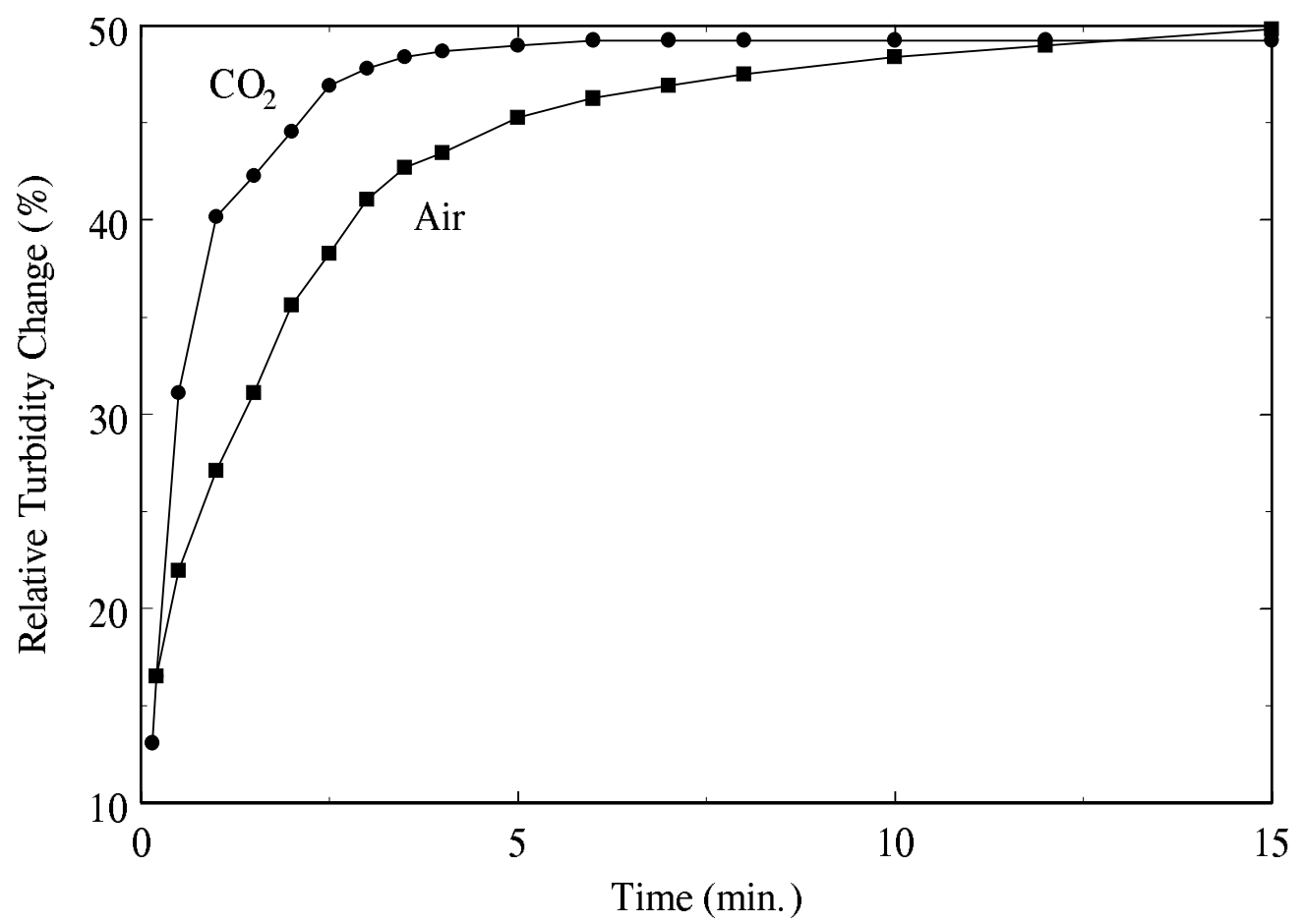

Figure 5. Effect of gas type on the agglomeration of Pittsburgh No. 8 coal.

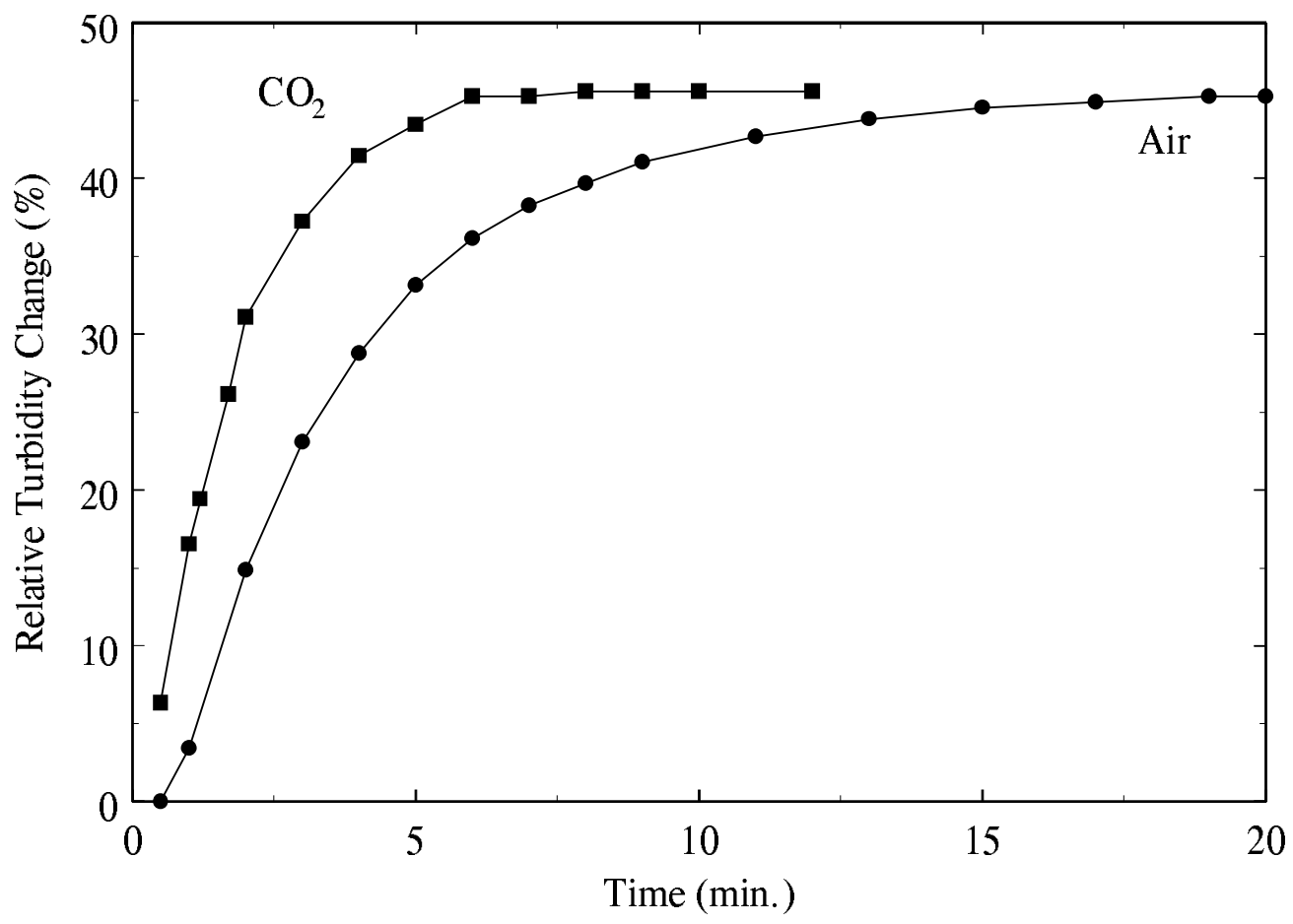

Figure 6. Effect of gas type on the agglomeration of Upper Freeport coal. 


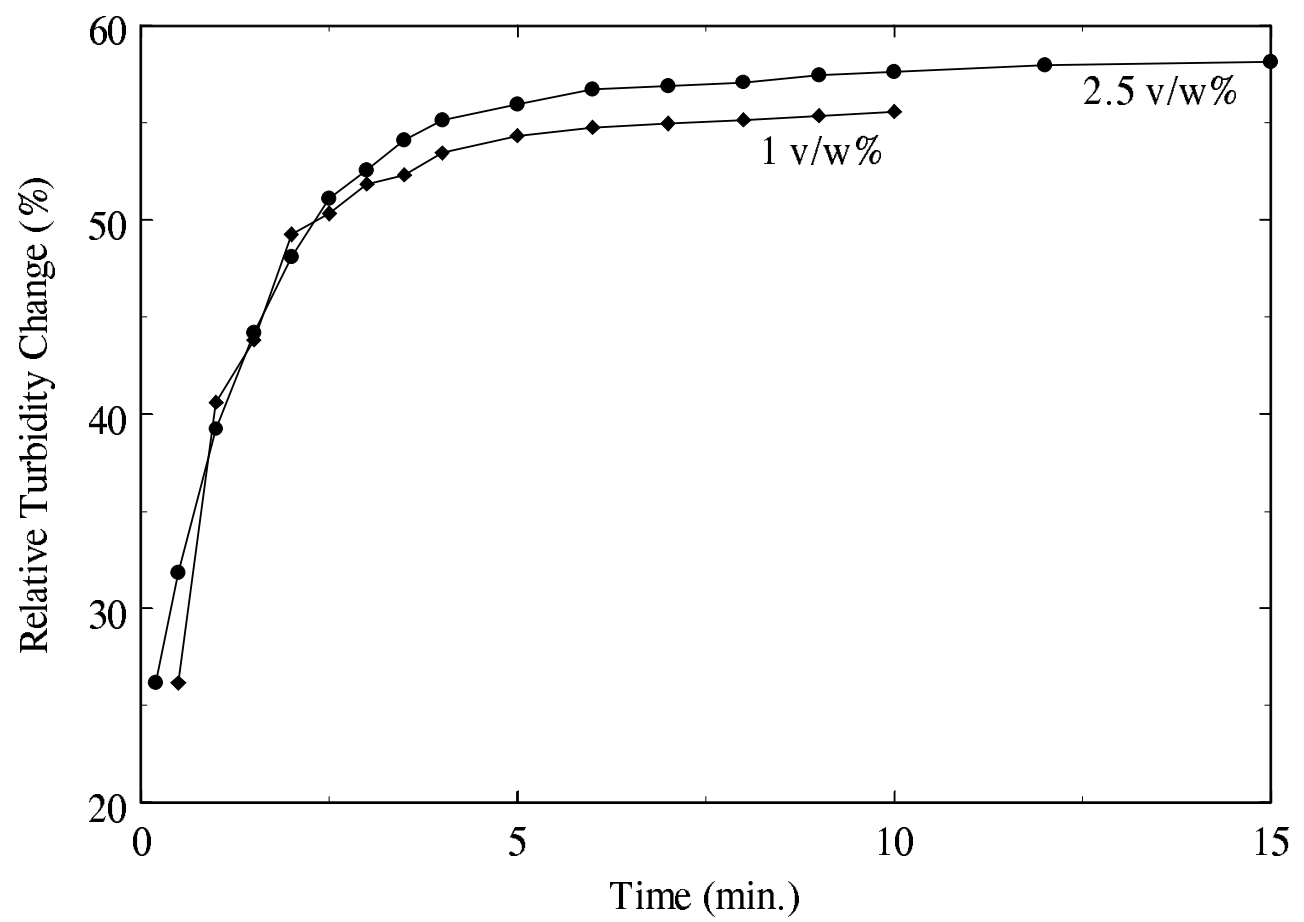

Figure 7. Effect of i-octane concentration on the agglomeration of Pittsburgh No. 8 coal.

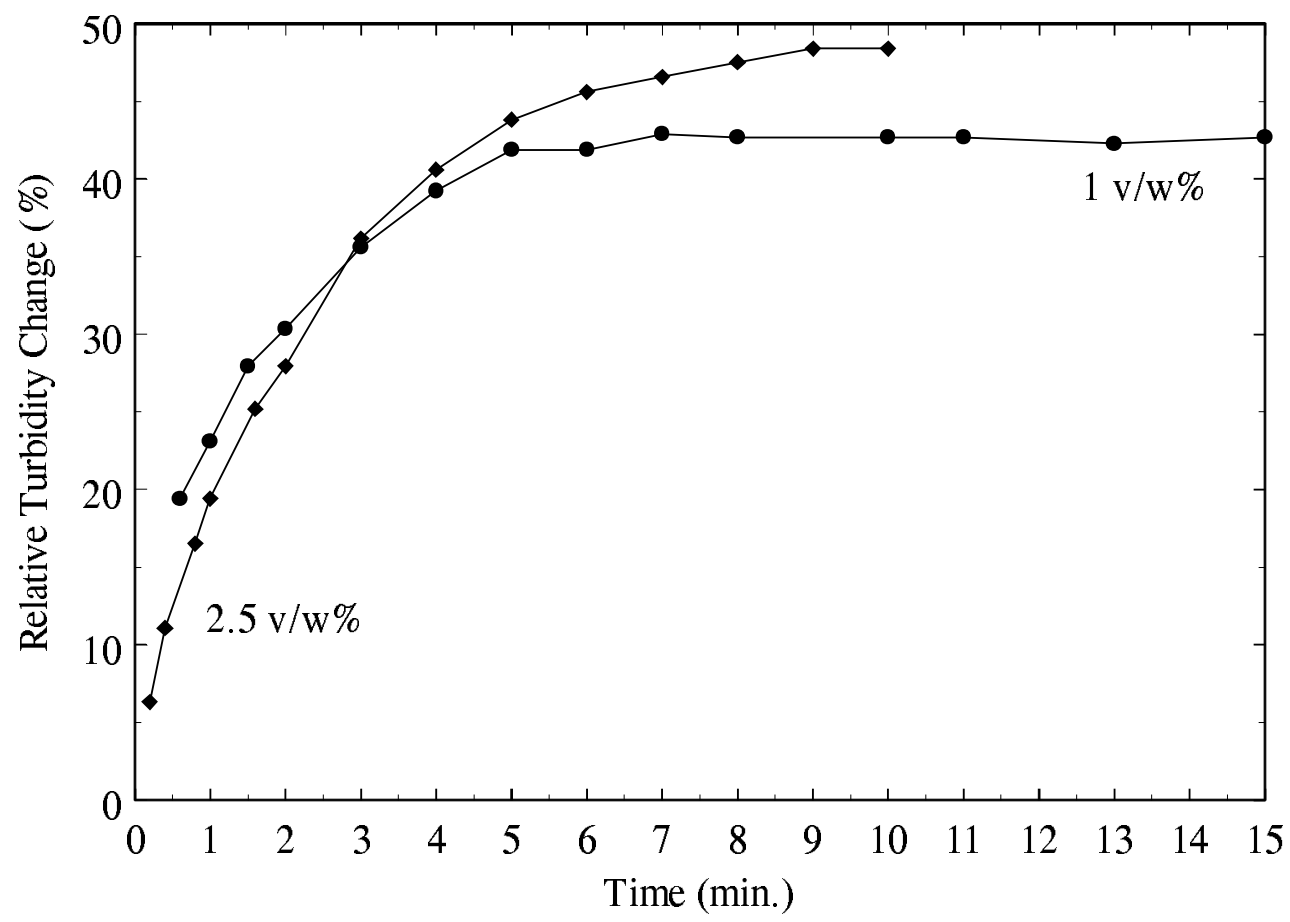

Figure 8. Effect of i-octane concentration on the agglomeration of Upper Freeport coal. 
The preceding results together with an examination of the product produced in various runs indicated that agglomeration was affected more by the concentration of microscopic gas bubbles than by the concentration of i-octane. A microscopic examination showed that the product usually consisted of spheroidal agglomerates which ranged from $15 \mu \mathrm{m}$ to $90 \mu \mathrm{m}$ in diameter and occasionally larger. Individual agglomerates appeared to consist of gas bubbles encapsulated in coal particles.

Several attempts to recover the agglomerates by screening were largely unsuccessful because the agglomerates were very fragile. A more promising method of recovery will be tested in the near future. This method allows the agglomerates to rise to the surface of the suspension at the end of an agglomeration test where they are removed by skimming. It takes advantage of the tendency for the agglomerates to float and for the nonagglomerated material to sink.

\section{CONCLUSIONS}

A series of experiments in which ultrafine-size coal particles were mixed with a colloidal dispersion of microscopic gas bubbles showed that the particles and bubbles combine to form microagglomerates that appear to consist of bubbles encapsulated in particles. The process is facilitated by a small amount of i-octane, which appears to promote the dispersion of gas bubbles in water and probably enhances the hydrophobicity of the coal surface. Similar results were achieved with both Pittsburgh No. 8 coal and Upper Freeport coal. The apparent rate of agglomeration seems to depend on the concentration of microscopic gas bubbles and to a much lesser extent on the concentration of i-octane. 


\section{REFERENCE}

1. T. D. Wheelock, M. Shen, and R. Abbott, "Coal Cleaning by Gas Agglomeration," Semi-Annual Technical Progress Report, for Oct. 1, 1997, to Mar. 31, 1998, Iowa State University, Ames, Iowa. 